\section{INHIBITION OF MILD STEEL CORROSION IN FORMIC ACID BY THIOUREA, 2-AMINO [4-p-CHLORO PHENYL] THIAZOLE AND DIFFERENT DERIVATIVES OF THEIR} CONDENSATION PRODUCTS

\section{Archana Gupta and M.M. Singh}

Department of Applied Chemistry, Institute of Technology, Banaras Hindu University, Varanasi - 221 005, (INDIA)

\section{ABSTRACT}

The inhibitive effect of thiourea, 2-amino [4-p-chlorophenyl] thiazole and different derivatives of their condensation products, N-2[4-pchlorophenyl] 2-thiazolyl] thiocarbamide on the corrosion of mild steel in $20 \%$ formic acid solution has been studied using weight loss and electrochemical polarisation techniques. Different concentrations of inhibitors and temperatures have been tested. The inhibition efficiencies calculated by both the techniques are in fairly good agreement except at higher concentrations of some inhibitors. The results observed have been discussed in the light of the molecular structures of the compounds and their adsorption on the surface of the corroding metal. All the inhibitors have been found to be good inhibitors. The polarisation measurements indicate that these inhibitors influence both anodic and cathodic reactions and thereby they contribute to reduce the corrosion rate.

Keywords : Mild steel, corrosion inhibition, formic acid, thiourea, thiazole, thiocarbamides.

\section{INTRODUCTION}

Corrosion of mild steel in organic acids is an active area of research. Organic compounds containing $\mathrm{N}$ and $\mathrm{S}$ have proved to be good inhibitors for the prevention of corrosion under acidic conditions (1-4). Thiourea (4-7) and thiazoles (8-9) have been recognised as inhibitors for corrosion of many metals in different inorganic and organic acidic media. Improvement in the inhibitive performance due to products resulting from condensing two different inhibitor molecules has also been reported earlier for various metals in different environments (10-11). Thus, it is interesting to investigate the improved performance of the condensation products of thiourea and some of the thiazoles as corrosion inhibitors of mild steel in formic acid solutions.

In the present investigation. the inhibitive effect of thiourea and 2amino [4-p-chlorophenyl] thiazole separately and of their condensation product, N-2[4-p-chlorophenyl] 2-thiazolyl] thiocarbamide, with different groups attached to it, on the corrosion of mild steel in 20 percent formic acid solution have been studied at 25.35 and $45^{\circ} \mathrm{C}$.

\section{EXPERIMENTAL}

Mild steel of composition C- $0.12 \%$, Mn- $0.11 \%$, Si- $-0.02 \%$, P- $0.02 \%$, S$0.02 \%, \mathrm{Ni}-0.02 \%, \mathrm{Cu}-0.01 \% \mathrm{Cr}-0.01 \%$ and remainder $\mathrm{Fe}$ was used for the preparation of test electrodes. Analytical grade formic acid and double distilled water was used in the preparation of the experimental solution. Thiourea, 2-amino [4-p-chlorophenyl]-thiazole, 2-amino [4-p-chlorophenyl] thiocarbamide. N-2 [4-p-chlorophenyl].5-phenyl azothiazolyl] thiocarbamide, $\mathrm{N}-2$ [4-p-chlorophenyl] 5-o-methyl phenyl azothiazolyl] thiocarbamide and N- 
2 [4-p-chlorophenyl] 5-o-methoxy phenyl azothiazolyl] thiocarbamide were synthesized in the laboratory and were recrystallized before use.

For weight loss experiments, specimens of $3 \times 3 \mathrm{~cm}$ were mechanically polished with $1 / 0$ to $4 / 0$ grade emmery papers followed by cleaning with soap and finally degreased with acetone. The specimens were dipped in $300 \mathrm{ml}$ of $20 \%$ formic acid without and with inhibitors for 24 hours. The loss in weight was determined after removing the specimens from the electrolyte. The test electrodes were washed thoroughly with distilled water, dried and weighed. Inhibition efficiencies were calculated from weight loss (2) and electrochemical techniques (12).

For electrochemical studies electrodes of $1 \times 1 \mathrm{~cm}$ with a $4 \mathrm{~cm}$ long tag for electrical contact were used. The part of the stem adjacent to the electrode was coated with a lacquer. In a three necked glass assembly, platinum foil of size $2 \times 2 \mathrm{~cm}$ and a Luggin type saturated calomel electrode were used as counter and reference electrodes. respectively. Potentiostatic polarisation experiments in nondeaerated and unstirred solution without any salt were carried out using a Wenking Model POS 73. The addition of up to $0.5 \mathrm{M}$ sodium formate to $20 \%$ formic acid was not considered since it does not affect the anodic and cathodic polarisation curves to any appreciable degree. The shape of these curves remains identical, both in the presence and the absence of the salt (13). Therefore, sodium formate was not added to the formic acid for the inhibition study: The steady state potential was recorded after it attained a constant value. All the experiments were performed in an air thermostat with an accuracy of $\pm 0.2^{\circ} \mathrm{C}$

\section{RESULTS AND DISCUSSION}

The inhibition efficiencies of thiourea (additive-I), 2-amino [4-pchlorophenyl] thiazole (additive-II), N-2[4-p-chlorophenyl] 2-thiazolyl] thiocarbamide (additive-III), N-2 [4-p-chlorophenyl] 5-phenyl azothiazolyl] thiocarbamide (additive-IV). N-2[4-p-chlorophenyl] 5-o-methylphenyl azothiazolyl] thiocarbamide (additive-V) and N-2 [4-p-chlorophenyl] 5-omethoxyphenyl azothiazolyl] thiocarbamide (additive-VI) at their different concentrations $(50,100,150,200$ and $250 \mathrm{ppm})$ evaluated by weight loss and electrochemical techniques have been recorded and are presented in Table 1. The percentage inhibition efficiency calculated by both techniques are in fairly good agreement. The variation in the inhibition efficiency of all the tested inhibitors with their concentration at $25^{\circ} \mathrm{C}$ has been illustrated in Fig. 1.

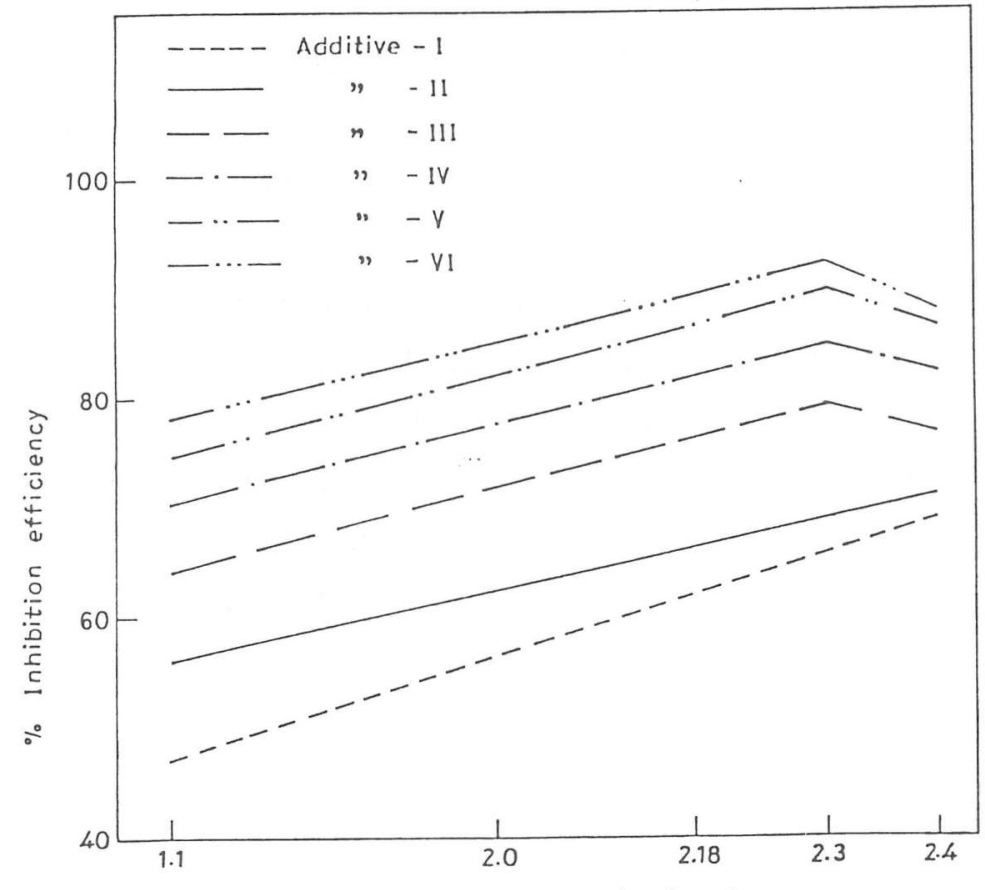

log Conceritration (ppm)

Fig. 1: Variation in \% inhibition efficiency with concentration of the inhibitors at $25^{\circ} \mathrm{C}$ 
Table 1: Inhibition efficiency (\%IE) of the inhibitors at their different concentrations for the corrosion of mild steel in 20\% formic acid by weight loss and electrochemical techniques at different temperatures.

\begin{tabular}{|c|c|c|c|c|c|c|}
\hline \multirow{3}{*}{$\begin{array}{l}\text { Inhibitors } \\
\text { and } \\
\text { concentrat } \\
\text { ion (ppm) }\end{array}$} & \multicolumn{6}{|c|}{$\%$ IE } \\
\hline & \multicolumn{2}{|c|}{$25^{\circ} \mathrm{C}$} & \multicolumn{2}{|c|}{$35^{\circ} \mathrm{C}$} & \multicolumn{2}{|c|}{$45^{\circ} \mathrm{C}$} \\
\hline & $\begin{array}{c}\text { Weight } \\
\text { loss }\end{array}$ & $\begin{array}{c}\text { Electro } \\
\text { chemical }\end{array}$ & $\begin{array}{l}\text { Weight } \\
\text { loss }\end{array}$ & $\begin{array}{l}\text { Electro } \\
\text { chemical }\end{array}$ & $\begin{array}{l}\text { Weight } \\
\text { loss }\end{array}$ & $\begin{array}{c}\text { Electro } \\
\text { chemical }\end{array}$ \\
\hline \multicolumn{7}{|l|}{ Thiourea } \\
\hline 50 & 47.23 & 45.05 & 52.76 & 51.02 & 54.55 & 54.29 \\
\hline 100 & 55.70 & 54.29 & 61.29 & 61.09 & 63.22 & 63.69 \\
\hline 150 & 62.54 & 61.10 & 63.59 & 64.52 & 65.29 & 66.89 \\
\hline 200 & 65.47 & 65.32 & 66.59 & 66.12 & 69.42 & 69.80 \\
\hline 250 & 68.08 & 69.10 & $70.7 t$ & 71.82 & 72.72 & 72.46 \\
\hline \multicolumn{7}{|c|}{ 2-amino [4-p-chlorophenyl] thiazole } \\
\hline 50 & $56.35^{2}$ & 56.35 & 62.67 & 62.85 & 65.70 & 65.33 \\
\hline 100 & 61.56 & 61.10 & 67.28 & 66.12 & 69.83 & 69.80 \\
\hline 150 & 65.80 & 63.69 & 70.96 & 70.49 & 73.76 & 74.30 \\
\hline 200 & 67.43 & 66.89 & 72.58 & 72.46 & 75.21 & 76.01 \\
\hline 250 & 70.03 & 71.16 & 76.50 & 74.30 & 78.93 & 77.09 \\
\hline \multicolumn{7}{|c|}{ N-2 [4-p-chlorophenyl] 2-thiazolyl] thiocarbamide } \\
\hline 50 & 61.89 & 61.98 & 69.12 & 70.49 & 71.07 & 71.16 \\
\hline 100 & 72.64 & 72.46 & 79.72 & 78.12 & 82.44 & 80.05 \\
\hline 150 & 76.87 & 75.45 & 82.49 & 82.62 & 85.12 & 83.78 \\
\hline 200 & 79.15 & 78.12 & 85.02 & 84.51 & 88.02 & 87.18 \\
\hline 250 & 76.22 & 80.05 & 82.94 & 86.20 & 84.50 & 88.52 \\
\hline \multicolumn{7}{|c|}{ N-2 [4-p-chlorophenyl] 5-phenyl azothiazolyl] thiocarbamide } \\
\hline 50 & 68.08 & 69.10 & 73.27 & 72.46 & 76.03 & 76.01 \\
\hline 100 & 78.83 & 78.12 & 83.87 & 83.02 & 86.78 & 85.55 \\
\hline 150 & 83.06 & 82.62 & 85.71 & 85.21 & 89.26 & 88.52 \\
\hline 200 & 85.02 & 84.15 & 88.94 & 87.12 & 90.91 & 89.04 \\
\hline 250 & 82.41 & 86.20 & 84.33 & 88.25 & 87.19 & 90.88 \\
\hline \multicolumn{7}{|c|}{$\mathrm{N}$-2 [4-p-chlorophenyl] 5-o-methyl phenyl azothiazolyl] thiocarbamide } \\
\hline 50 & $74.59^{\circ}$ & 73.70 & 78.80 & 78.12 & 81.40 & 80.05 \\
\hline 100 & 83.39 & 83.40 & 88.25 & 87.12 & 90.29 & 89.04 \\
\hline 150 & 85.99 & 86.20 & 89.63 & 89.04 & 91.12 & 91.29 \\
\hline 200 & 89.57 & 89.53 & 91.01 & 90.23 & 92.36 & 91.87 \\
\hline 250 & 86.31 & 90.45 & 89.17 & 91.09 & 90.08 & 92.76 \\
\hline \multicolumn{7}{|c|}{ N-2 [4-p-chlorophenyl] 5-0-methoxy phenyl azothiazolyl] thiocarbamide } \\
\hline 50 & 77.85 & 78.12 & 82.02 & 81.38 & 83.06 & 82.62 \\
\hline 100 & 86.32 & 86.82 & 90.32 & 88.25 & 91.32 & 90.88 \\
\hline 150 & 90.55 & 90.45 & 91.71 & 91.49 & 93.39 & 92.76 \\
\hline 200 & 91.85 & 91.29 & 93.31 & 92.59 & 94.42 & 93.54 \\
\hline 250 & 88.27 & 92.06 & 88.47 & 93.54 & 90.29 & 94.50 \\
\hline
\end{tabular}

The inhibition efficiency of additives were found to increase continuously with increase in their concentration. However, the percentage inhibition efficiencies of additive-III to VI determined by weight loss method showed a declining tendency above the concentration of $200 \mathrm{ppm}$. The decrease in inhibition efficiency between 200 and $250 \mathrm{ppm}$ for these additives is observed at each experimental temperature. Surprisingly such a decrease in inhibition efficiency at $250 \mathrm{ppm}$ was not observed when evaluated by electrochemical method, instead it increased continuously at all temperatures. It is difficult to explain this discrepancy in the inhibition efficiency values calculated by using different techniques because both positive and negative difference between two values for each inhibitor at their different concentrations has been observed.

Inhibition efficiencies of the order of 65 and 67 percent were obtained at $25^{\circ} \mathrm{C}$ and at $200 \mathrm{ppm}$ of the additives I and II respectively, by weight loss and electrochemical techniques. However, the condensation product of these two additives, additive-III, exhibited 79 percent inhibition efficiency at the same concentration and temperature. The inhibition efficiency of the condensation product further improved from 79 to 92 percent as derivatives of this compound synthesized on substituting di-azophenyl, di-azo-o-methyl phenyl and di-azo-o-methoxy phenyl groups of the thiazole of the condensation product were used as inhibitor. Successive increase in the inhibition efficiency of the derivatives from IV to VI is in agreement with the theoretical prediction. Thus, the observed inhibition efficiency at different concentrations and temperatures follow the trend : Additive VI $>$ V $>$ IV $>$ III $>$ II $>$ I. An increase in temperature invariably increases the inhibition efficiency of all inhibitors at all concentrations.

The effectiveness of these inhibitors may be explained assuming the adsorption process as the cause of inhibition. The extent of adsorption of different inhbitors at a fixed concentration would depend on the surface area of the inhibitor molecules and the number and position of active centres such as $\mathrm{N}, \mathrm{S}$ and $\mathrm{O}$ atoms along with delocalised $\pi$ electron density on the aromatic ring. The structures of the tested inhibitors are : 
(1) Thiourea $\mathrm{NH}_{2}-\stackrel{\mathrm{S}}{\mathrm{II}}-\mathrm{NH}_{2}$

(2) 2 - Amino $[4-p-$ chlorophenyl $]$ thiazole

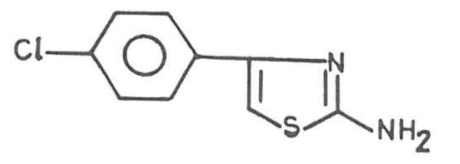

(3) N-2 [4-p-chlorophenyl] 2 - thiazolyl $]$ thiocarbamide

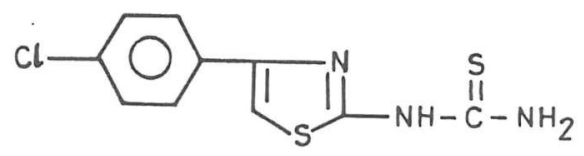

(4) N-2 [4-p-chlorophenyl] 5-phenyl azothiazolyl $]$ thiocarbamide

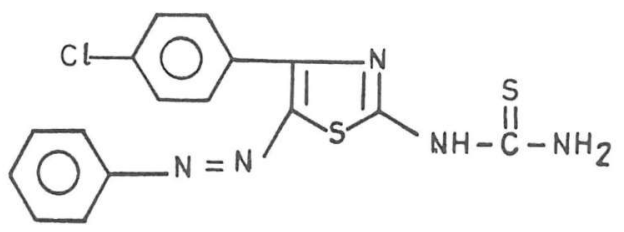

(5) N-2 [4-p-chlorophenyl $] 5-0$-methyl phenyl azothiazolyl $]$ thiocarbamide

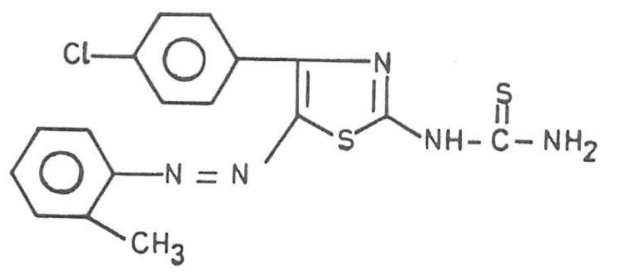

(6) N-2 [4-p-chlorophenyl $] 5-0$-methoxy phenyl azothiazolyl $]$ thiocarbamide

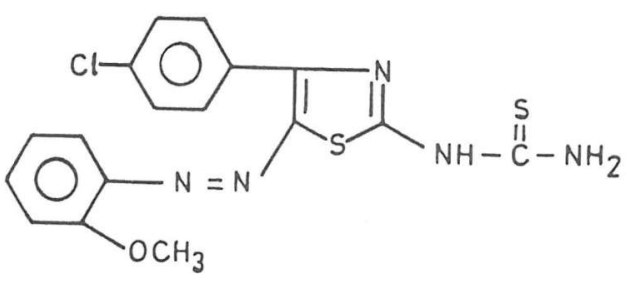

The inhibition efficiency data recorded in Table 1 reveals that on increasing the concentration of thiourea from 50 to $250 \mathrm{ppm}$, inhibition efficiency increases from 47 to 68 percent. With a rise in temperature from 25 to $45^{\circ} \mathrm{C}$ the percentage inhibition efficiency increases up to 72 percent at 250 ppm. Thus, thiourea may be considered to show appreciable inhibition efficiency at $250 \mathrm{ppm}$ and at higher temperature the efficiency is even slightly improved. The adsorption of thiourea on the corroding surface being considered as the cause of inhibition, it could take place via functional nitrogen and sulphur atoms. Lower values of inhibition efficiency may be attributed to the smaller size of the additive which could however be improved by substituting hydrogen atoms in the molecule with other groups so that the number of active centres and lone pairs of electrons at these sites as well as the surface area of the molecule is appreciably increased $(3,5)$.

On the other hand. inhibition efficiency of 2-amino[4-p-chlorophenyl] thiazole is greater (56\%) than that of thiourea (47\%), at $50 \mathrm{ppm}$. In fact, additive - II has more active centres and larger surface area than thiourea. The adsorption of additive-II may take place via functional $\mathrm{N}$ and $\mathrm{S}$ atoms as well as through the delocalised $\pi$ electrons of the phenyl groups and thus, covering larger surface area. Consequently, an increase in inhibition efficiency is expected when thiourea is replaced by this compound. The results of the present investigation are in agreement with the theoretical prediciton. In order to achieve further increase in inhibition efficiency additive III to VI were synthesized by condensing additive I and II and then preparing its different derivatives.

The additives III to VI can be considered to be made up of both thiourea and 2-amino [4-p-chlorophenyl] thiazole, in parts. These additives should show greater inhibition efficiency than additive I and/or II. It is to be 
noticed that additive III shows an increase in inhibition efficiency over any of the inhibitors I or II. The inhibition efficiency of additive III is quite large, $79 \%$, in comparison to the respective values $65 \%$ and $67 \%$ for additives I and II, at $200 \mathrm{ppm}$. This increase in inhibition efficiency may be attributed to increase in the number of active centres as well as the surface area. The inhibitor has two ' $\mathrm{S}$ ' and three ' $\mathrm{N}$ ' atoms as active centres and in addition a phenyl group. Looking at the structure of the additive III, it appears that it should have shown much larger inhibition efficiency than that actually observed. But, depending upon the geometry of the molecule, all the active centres may not be able to participate in the coordination bonding with the metal ions on the surface and hence, the expected result is not achieved. Nevertheless, the increase in inhibition efficiency is the indicative of the fact that larger surface area of the electrode is covered by the molecules of the third additive than those covered by any of the first two additives.

Further, an increase in the inhibition efficiency by $6 \%$ is observed when di-azophenyl group is substituted in the additive-III. In di-azophenyl group two nitrogen atoms are present as the key atoms for adsorption. In addition, the $\pi$ electron density of benzene ring may also enhance the adsorbability of the molecules. This explains the higher inhibition efficiency shown by the additive-IV in comparison to that of the additive-III.

The di-azophenyl group being common to all additives from IV to VI gives further improvement in the inhibition efficiency due to an increase in the $\pi$ electron density on phenyl ring by substitutionof electron donating groups such as methyl $\left(-\mathrm{CH}_{3}\right)$ and methoxy $\left(-\mathrm{OCH}_{3}\right)$ groups on the phenyl ring. Hence, further improvement in IE shown by additive $\mathrm{V}$ and VI is due to increased electron density due to the phenyl ring. The additive VI shows larger inhibition efficiency than additive V. This enhancement in inhibition efficiency is conceivable in the light of better electron donating property of
$-\mathrm{OCH}_{3}$ than that of $-\mathrm{CH}_{3}$ group. The relative change in the inhibition efficiency observed during the investigation by successively changing the additive from IV to VI indicates that it is the phenyl ring of the dia-azophenyl group which is mainly involved in the adsorption process. The two nitrogen atoms would have been away from the electrode surface to have any impact in the extent of adsorption.

The decrease in inhibition efficiency at $250 \mathrm{ppm}$ for additive III to VI would have occurred due to mutual interaction between inhibitor molecules adsorbed at the adjacent sites. The observed data reveal that this is true particularly for bulky molecules and it is quite obvious. It is evident from data on Table 1 that an increase in temperature and concentration leads to an improvement in the protective power for all the additives. Similar increase in inhibitive efficiency of thiourea and its compound with the increase in temperature has been reported earlier for $\mathrm{Al}-\mathrm{HNO}_{3}$ system (3). This enhancement in inhibitive efficiency at higher temperatures has been attributed to the higher activation energy for the adsorption and the higher rate of diffusion of bulky inhibitor molecules, at elevated temperatures, from the bulk of solution to the interface (1t).

The anodic polarisation behaviour of mild steel was studied in 20 percent formic acid containing different concentrations of additives at temperatures 25,35 and $45^{\circ} \mathrm{C}$. The curves in Fig. 2 illustrate the anodic polarisation behaviour of mild steel in the presence of 50,100,150,200 and $250 \mathrm{ppm}$ of additive-VI at $25^{\circ} \mathrm{C}$. The shape of the curve is not modified on adding the additives or increasing their concentrations. However. on increasing the concentration of the inhibitor, the curves are gradually shifted towards lower current density region. The nature of the anodic polarisation curves observed for other additives exhibit similar trend at all the concentrations and temperatures $\left(25.35\right.$ and $\left.45^{\circ} \mathrm{C}\right)$. 


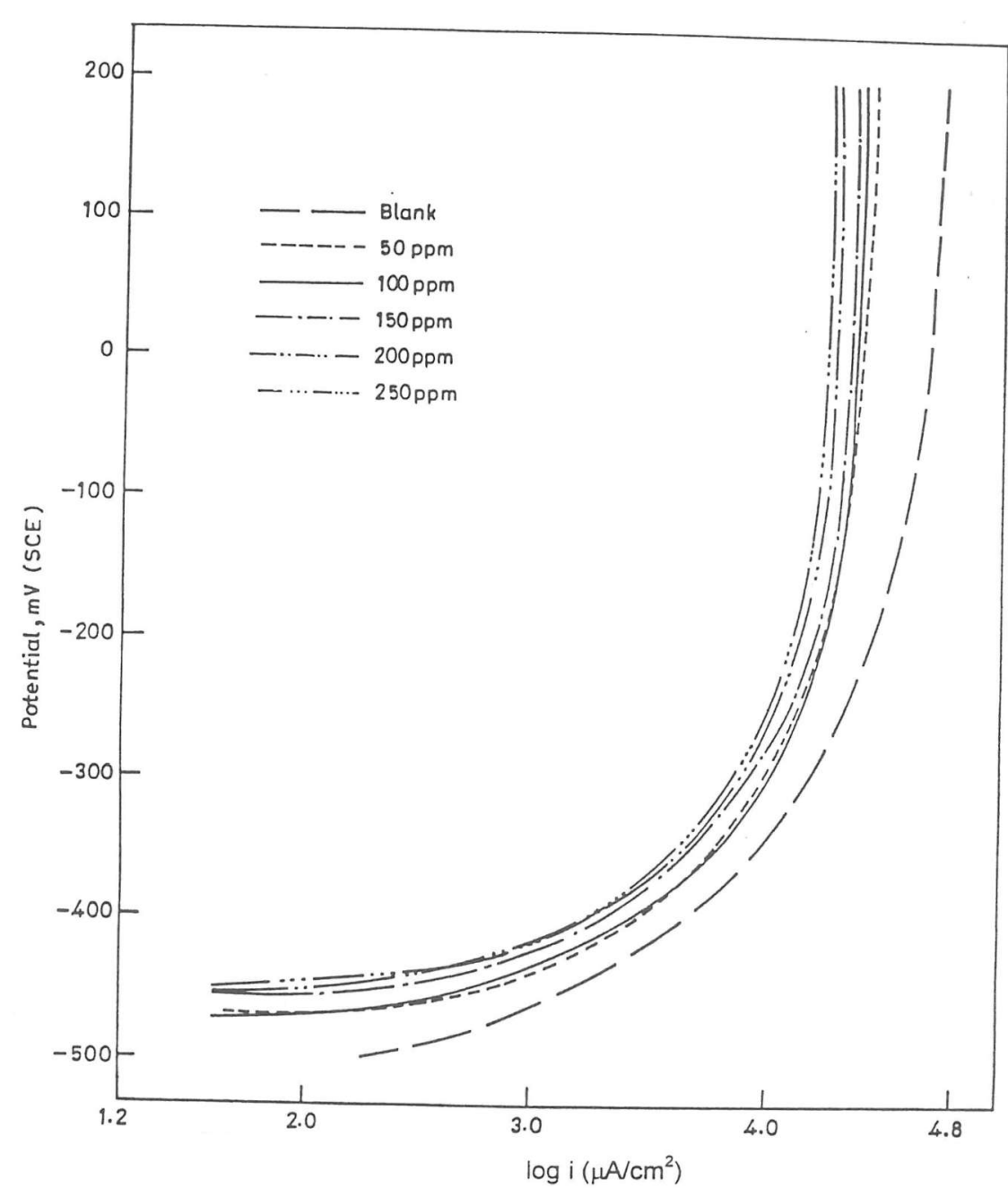

Fig. 2: Anodic polarisation curves for different concentrations of additive - VI at $25^{\circ} \mathrm{C}$

It is realized from these observations that the additive molecules retard the corrosion process without changing the mechanism of corrosion. The magnitude of the shift in current density is directly proportional to the concentration of inhibitors, indicating that the inhibitive property of these compounds is concentration dependent.
Fig. 3 illustrates the potentiostatic anodic polarisation curves for all the additives studied at $25^{\circ} \mathrm{C}$ and $250 \mathrm{ppm}$ (similar curves were obtained at 35 and $45^{\circ} \mathrm{C}$ ). The shift towards lower current density was observed to be maximum for additive-VI indicating its maximum effectiveness with respect to its interference with anodic reaction. The observed shift in anodic polarisation curves due to each of the inhibitor follows the same trend as that followed by

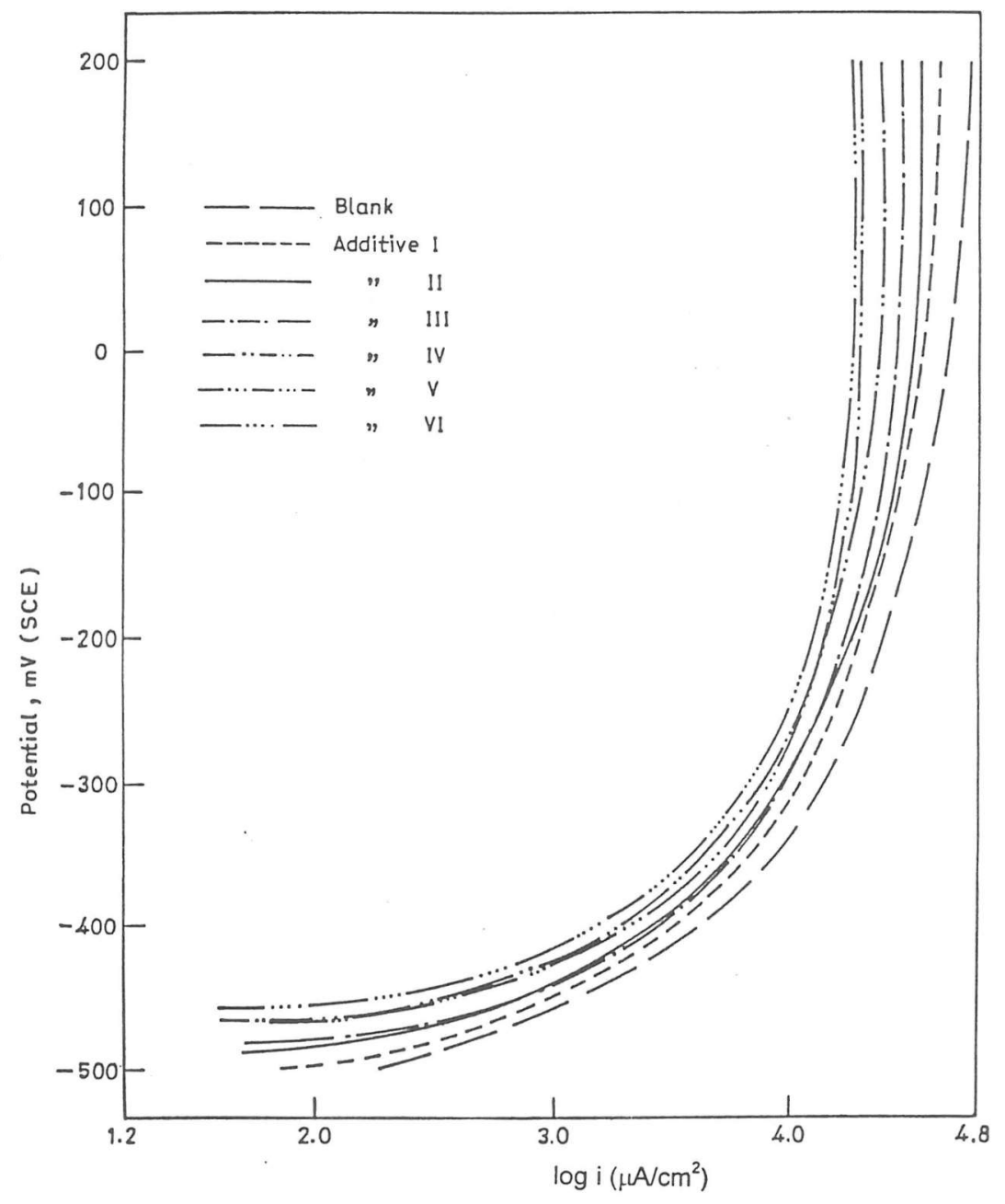

Fig. 3: Anodic polarisation curves of mild steel in the presence of different additives at $25^{\circ} \mathrm{C}$ 
their inhibition efficiencies.

The anodic parameters such as corrosion current $\left(i_{\text {corr }}\right)$, corrosion potential $\left(\mathrm{E}_{\text {corr }}\right)$, limiting current $\left(\mathrm{i}_{\mathrm{L}}\right)$ and the ratio of limiting current with and without inhibitor $\left(i_{L} / i_{L}{ }^{0}\right)$ in the electrolyte obtained from the polarisation curves are presented in Tables 2.3 and 4 at temperatures 25,35 and $45^{\circ} \mathrm{C}$, respectively for all the additives. It is apparent from the data in these tables that there is a decrease in $i_{\text {corr }}$. $i_{L}$ and $i_{L} / i_{L}{ }^{0}$ values with increase in the concentration of the additives at each temperature. The decrease in $i_{\text {corr }}$ with the addition of the inhibitor and of the ratio of limiting current densities with and without the addition of the inhibitors $\left(\mathrm{i}_{\mathrm{L}} / \mathrm{i}_{\mathrm{L}}{ }^{\circ}\right)$ may be explained on the basis of the adsorption of these molecules on electrode surface, thereby decreasing the surface area available for the anodic reaction. The displacement of $E_{\text {сопт }}$ in the presence of these inhibitors slightly in the positive direction is observed.

The cathodic polarisation curves of mild steel in the presence of different concentration of additive VI at $25^{\circ} \mathrm{C}$ are shown in Fig. 4. It is evident from the figure that on increasing the concentration of the additive cathodic polarisation curve shifts towards the lower current density region. The observed trend for other additives at all concentration and temperature is similar. Further, at a fixed concentration of $250 \mathrm{ppm}$, for different additives the relative downward shift is again in accordance to their inhibition efficiency as shown in Fig. 5. This indicates that all the additives are able to prevent the cathodic process along with the anodic process.

Thus, from the above discussion it may be concluded that adsorption phenomenon is mainly responsible for the inhibition caused by these molecules. Assuming that the area covered by the inhibitor is directly related to the reduction in the corrosion rate. the inhibition process should follow
Table 2: Corrosion parameters from anodic polarisation curves of mild steel in $20 \%$ formic acid containing different concentrations of additives, at $25^{\circ} \mathrm{C}$.

\begin{tabular}{|c|c|c|c|c|c|}
\hline $\begin{array}{l}\text { Inhibitors and } \\
\text { concentration }(\mathrm{ppm})\end{array}$ & $\mathrm{i}_{\text {Corr }}\left(\mu \mathrm{A} / \mathrm{cm}^{2}\right)$ & $\mathrm{i}_{\text {Corr }} / \mathrm{i}_{\text {Corr }}{ }^{\circ}$ & $\mathrm{E}_{\text {Corr }}(\mathrm{mV})$ & $\mathrm{i}_{\mathrm{L}}\left(\mathrm{mA} / \mathrm{cm}^{2}\right)$ & $\mathrm{i}_{\mathrm{L}} / \mathrm{i}_{\mathrm{L}}{ }^{0}$ \\
\hline Blank & 288.40 & - & -520 & 56.23 & - \\
\hline \multicolumn{6}{|l|}{$\begin{array}{l}\text { Blank } \\
\text { Thiourea }\end{array}$} \\
\hline 50 & 158.49 & 0.55 & -515 & 52.48 & 0.93 \\
\hline 100 & 131.83 & 0.46 & -510 & 50.12 & 0.89 \\
\hline 150 & 112.20 & 0.39 & -510 & 45.71 & 0.81 \\
\hline 200 & 100.00 & 0.35 & -505 & 43.65 & 0.78 \\
\hline 250 & 89.13 & 0.31 & -505 & 41.69 & 0.74 \\
\hline \multicolumn{6}{|c|}{ 2-amino [4-p-chlorophenyl] thiazole } \\
\hline 50 & 125.89 & 0.44 & -518 & 45.71 & 0.81 \\
\hline 100 & 112.20 & 0.39 & -515 & 43.65 & 0.78 \\
\hline 150 & 104.71 & 0.36 & -510 & 39.81 & 0.71 \\
\hline 200 & 95.50 & 0.33 & -508 & 38.02 & 0.68 \\
\hline 250 & 83.18 & 0.29 & -508 & 36.31 & 0.65 \\
\hline \multicolumn{6}{|c|}{$\begin{array}{ccc}250 & 83.18 & 0.29 \\
\mathrm{~N}-2 & \text { 4-p-chlorophenyl] 2-thiazolyl] thiocarbamide }\end{array}$} \\
\hline 50 & 109.65 & 0.38 & -510 & 39.81 & 0.71 \\
\hline 100 & 79.43 & 0.28 & -512 & 38.02 & 0.68 \\
\hline 150 & 70.79 & 0.25 & -508 & 34.64 & 0.62 \\
\hline 200 & 63.10 & 0.22 & -505 & 31.62 & 0.56 \\
\hline 250 & 57.54 & 0.20 & -505 & 30.20 & 0.54 \\
\hline \multicolumn{6}{|c|}{$\mathrm{N}-2[4-\mathrm{p}$-chlorophenyl] 5-phenyl azothiazolyl] thiocarbamide } \\
\hline 50 & 89.13 & 0.31 & -512 & 34.64 & 0.62 \\
\hline 100 & 63.10 & 0.22 & -510 & 33.11 & 0.59 \\
\hline 150 & 50.12 & 0.17 & -508 & 30.20 & 0.54 \\
\hline 200 & 45.71 & 0.16 & -504 & 26.30 & 0.47 \\
\hline 250 & 39.81 & 0.14 & -504 & 25.12 & 0.45 \\
\hline \multicolumn{6}{|c|}{$\mathrm{N}-2$ [4-p-chlorophenyl] 5-0-methyl phenyl azothiazolyl] thiocarbamide } \\
\hline 50 & 75.86 & 0.26 & -510 & 31.62 & 0.56 \\
\hline 100 & 47.86 & 0.17 & -508 & 28.84 & 0.51 \\
\hline 150 & 39.81 & 0.14 & -508 & 25.12 & 0.45 \\
\hline 200 & 30.20 & 0.10 & -505 & 21.88 & 0.39 \\
\hline 250 & 27.54 & 0.10 & -502 & 19.95 & 0.35 \\
\hline \multicolumn{6}{|c|}{ 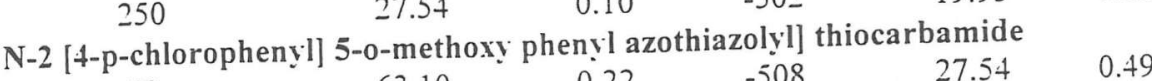 } \\
\hline 50 & 63.10 & 0.22 & -508 & 27.54 & 0.49 \\
\hline 100 & 38.02 & 0.13 & -505 & 25.12 & 0.45 \\
\hline 150 & 27.54 & 0.10 & -504 & 22.91 & 0.41 \\
\hline 200 & 25.12 & 0.09 & -500 & 19.05 & 0.34 \\
\hline 250 & 22.91 & 0.08 & -505 & 17.38 & 0.31 \\
\hline
\end{tabular}


Table 3: Corrosion parameters from anodic polarisation curves of mild steel in $20 \%$ formic acid containing different concentrations of additives, at $35^{\circ} \mathrm{C}$.

\begin{tabular}{|c|c|c|c|c|c|}
\hline $\begin{array}{l}\text { Inhibitors and } \\
\text { concentration (ppm) }\end{array}$ & $\mathrm{i}_{\text {Corr }}\left(\mu \mathrm{A} / \mathrm{cm}^{2}\right)$ & $\mathrm{i}_{\text {Corr }} / \mathrm{i}_{\text {Corr }}{ }^{\circ}$ & $\mathrm{E}_{\text {Corr }}(\mathrm{mV})$ & $\mathrm{i}_{\mathrm{L}}\left(\mathrm{mA} / \mathrm{cm}^{2}\right)$ & $i_{L} / i_{L}{ }^{0}$ \\
\hline Blank & 512.86 & - & -520 & 79.43 & - \\
\hline \multicolumn{6}{|l|}{ Thiourea } \\
\hline 50 & 251.19 & 0.49 & -512 & 54.95 & 0.69 \\
\hline 100 & 199.53 & 0.39 & -508 & 50.12 & 0.63 \\
\hline 150 & 181.97 & 0.35 & -505 & 47.86 & 0.60 \\
\hline 200 & 173.78 & 0.34 & -500 & 45.71 & 0.58 \\
\hline 250 & 144.54 & 0.28 & -490 & 43.65 & 0.55 \\
\hline \multicolumn{6}{|c|}{ 2-amino [4-p-chlorophenyl] thiazole } \\
\hline 50 & 190.55 & 0.37 & -510 & 52.48 & 0.66 \\
\hline 100 & 173.78 & 0.34 & -510 & 47.86 & 0.60 \\
\hline 150 & 151.36 & 0.30 & -506 & 45.71 & 0.58 \\
\hline 200 & 141.25 & 0.28 & -505 & 41.69 & 0.52 \\
\hline 250 & 131.83 & 0.26 & -500 & 39.81 & 0.50 \\
\hline \multicolumn{6}{|c|}{ N-2 [4-p-chlorophenyl] 2-thiazolyl] thiocarbamide } \\
\hline 50 & 151.36 & 0.30 & -505 & 45.71 & 0.58 \\
\hline 100 & 112.20 & 0.22 & -500 & 41.69 & 0.52 \\
\hline 150 & 89.13 & 0.17 & -498 & 39.81 & 0.50 \\
\hline 200 & 79.43 & 0.15 & -495 & 36.31 & 0.46 \\
\hline 250 & 70.79 & 0.14 & -492 & 34.64 & 0.44 \\
\hline \multicolumn{6}{|c|}{ N-2 [4-p-chlorophenyl] 5-phenyl azothiazolyl] thiocarbamide. } \\
\hline 50 & 141.25 & 0.28 & -508 & 39.81 & 0.50 \\
\hline 100 & 87.10 & 0.17 & -500 & 38.02 & 0.48 \\
\hline 150 & 75.86 & 0.15 & -495 & 34.64 & 0.44 \\
\hline 200 & 66.07 & 0.13 & $-49 ?$ & 33.11 & 0.42 \\
\hline 250 & 60.26 & 0.12 & -495 & 31.62 & 0.40 \\
\hline \multicolumn{6}{|c|}{ N-2 [4-p-chlorophenyl] 5-0-methyl phenyl azothiazolyl] thiocarbamide } \\
\hline 50 & 112.20 & 0.22 & -505 & 38.02 & 0.48 \\
\hline 100 & 66.07 & 0.13 & -508 & 36.31 & 0.46 \\
\hline 150 & 56.23 & 0.11 & -500 & 33.11 & 0.42 \\
\hline 200 & 50.12 & 0.10 & -495 & 30.20 & 0.38 \\
\hline 250 & 45.71 & 0.09 & -490 & 28.84 & 0.36 \\
\hline \multicolumn{6}{|c|}{$\mathrm{N}$-2 [4-p-chlorophenyl] 5-o-methoxy phenyl azothiazolyl] thiocarbamide } \\
\hline 50 & 95.50 & 0.17 & -500 & 36.31 & 0.46 \\
\hline 100 & 60.26 & 0.12 & -505 & 33.11 & 0.42 \\
\hline 150 & 43.65 & 0.09 & -500 & 30.20 & 0.38 \\
\hline 200 & 38.02 & 0.07 & -490 & 28.18 & 0.35 \\
\hline 250 & 33.11 & 0.06 & -485 & 26.30 & 0.33 \\
\hline
\end{tabular}

Table 4: Corrosion parameters from anodic polarisation curves of mild steel in $20 \%$ formic acid containing different concentrations of additives. at $45^{\circ} \mathrm{C}$.

\begin{tabular}{|c|c|c|c|c|c|}
\hline $\begin{array}{l}\text { Inhibitors and } \\
\text { concentration (ppm) }\end{array}$ & $\mathrm{i}_{\text {Cоrт }}\left(\mu \mathrm{A} / \mathrm{cm}^{2}\right)$ & $\mathrm{i}_{\text {Corr }} / \mathrm{i}_{\text {Corr }}{ }^{\circ}$ & $\mathrm{E}_{\text {Corr }}(\mathrm{mV})$ & $\mathrm{i}_{\mathrm{L}}\left(\mathrm{mA} / \mathrm{cm}^{2}\right)$ & $\mathrm{i}_{\mathrm{L}} / \mathrm{i}_{\mathrm{L}}^{0}$ \\
\hline Blank & 870.96 & - & -535 & 100.00 & - \\
\hline \multicolumn{6}{|l|}{ Thiourea } \\
\hline 50 & 398.11 & 0.46 & -530 & 70.79 & 0.71 \\
\hline 100 & 316.23 & 0.36 & -520 & 63.09 & 0.63 \\
\hline 150 & 288.40 & 0.33 & -525 & 56.23 & 0.56 \\
\hline 200 & 263.03 & 0.30 & -518 & 50.12 & 0.50 \\
\hline 250 & 239.88 & 0.28 & -520 & 47.86 & 0.48 \\
\hline \multicolumn{6}{|c|}{ 2-amino [4-p-chlorophenyl] thiazole } \\
\hline 50 & 302.00 & 0.35 & -530 & 63.09 & 0.63 \\
\hline 100 & 263.03 & 0.30 & -525 & 57.54 & 0.58 \\
\hline 150 & 223.87 & 0.26 & -520 & 52.48 & 0.52 \\
\hline 200 & 208.93 & 0.24 & -525 & 47.86 & 0.48 \\
\hline 250 & 199.53 & 0.23 & -515 & 44.67 & 0.45 \\
\hline \multicolumn{6}{|c|}{ N-2 [4-p-chlorophenyl] 2-thiazolyl] thiocarbamide } \\
\hline 50 & 251.19 & 0.29 & -525 & 54.95 & 0.55 \\
\hline 100 & 173.78 & 0.20 & -518 & 50.12 & 0.50 \\
\hline 150 & 141.25 & 0.16 & -510 & 45.71 & 0.46 \\
\hline 200 & 112.20 & 0.13 & -508 & 41.69 & 0.42 \\
\hline 250 & 100.00 & 0.11 & -508 & 39.81 & 0.40 \\
\hline \multicolumn{6}{|c|}{ N-2 [4-p-chlorophenyl] 5-phenyl azothiazolyl] thiocarbamide } \\
\hline 50 & 208.93 & 0.24 & -520 & 52.48 & 0.52 \\
\hline 100 & 125.89 & 0.14 & -518 & 47.86 & 0.48 \\
\hline 150 & 100.00 & 0.11 & -525 & 43.65 & 0.44 \\
\hline 200 & 95.50 & 0.11 & -515 & 38.02 & 0.38 \\
\hline 250 & 79.43 & 0.09 & -510 & 36.31 & 0.36 \\
\hline \multicolumn{6}{|c|}{ N-2 [4-p-chlorophenyl] 5-o-methyl phenyl azothiazolyl] thiocarbamide } \\
\hline 50 & 173.78 & 0.20 & -515 & 47.86 & 0.48 \\
\hline 100 & 95.50 & 0.11 & -510 & 43.65 & 0.44 \\
\hline 150 & 75.86 & 0.09 & -508 & 39.81 & 0.40 \\
\hline 200 & 70.79 & 0.08 & -505 & 36.31 & 0.36 \\
\hline 250 & 63.10 & 0.07 & -505 & 33.11 & 0.33 \\
\hline \multicolumn{6}{|c|}{ N-2 [4-p-chlorophenyl] 5-0-methoxy phenyl azothiazolyl] thiocarbamide } \\
\hline 50 & 151.36 & 0.17 & -508 & 39.81 & 0.40 \\
\hline 100 & 79.43 & 0.09 & -505 & 38.02 & $0-38$ \\
\hline 150 & 63.10 & 0.07 & -500 & 34.64 & 0.35 \\
\hline 200 & 56.23 & 0.06 & -495 & 31.62 & 0.32 \\
\hline 250 & 47.86 & 0.05 & -490 & 30.20 & 0.30 \\
\hline
\end{tabular}




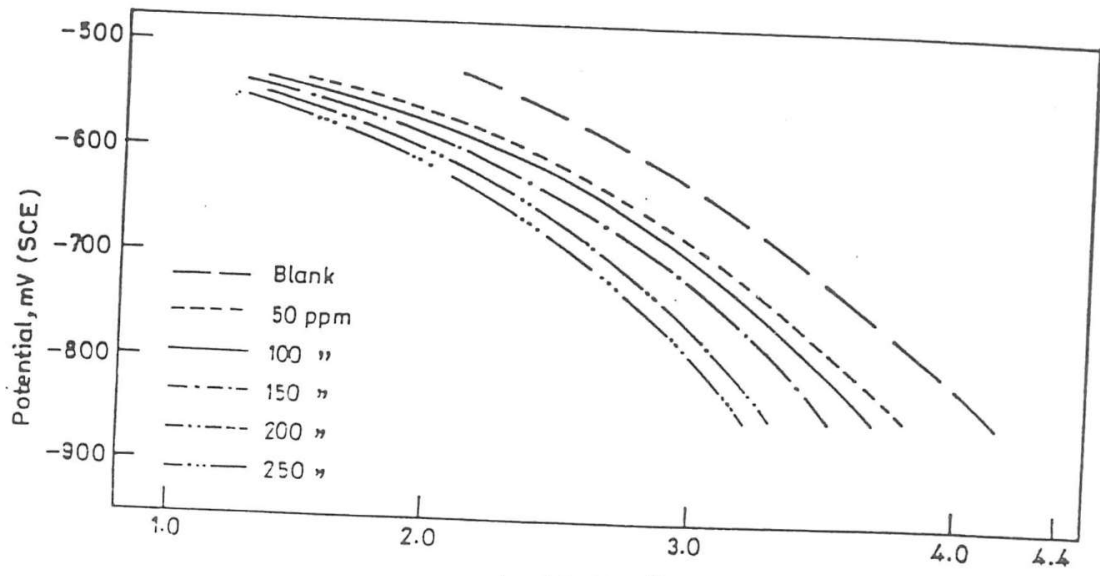

$\log i\left(\mu \mathrm{A} / \mathrm{cm}^{2}\right)$

Fig. 4: Cathodic polarisation curves for different concentrations of additive - VI at $25^{\circ} \mathrm{C}$

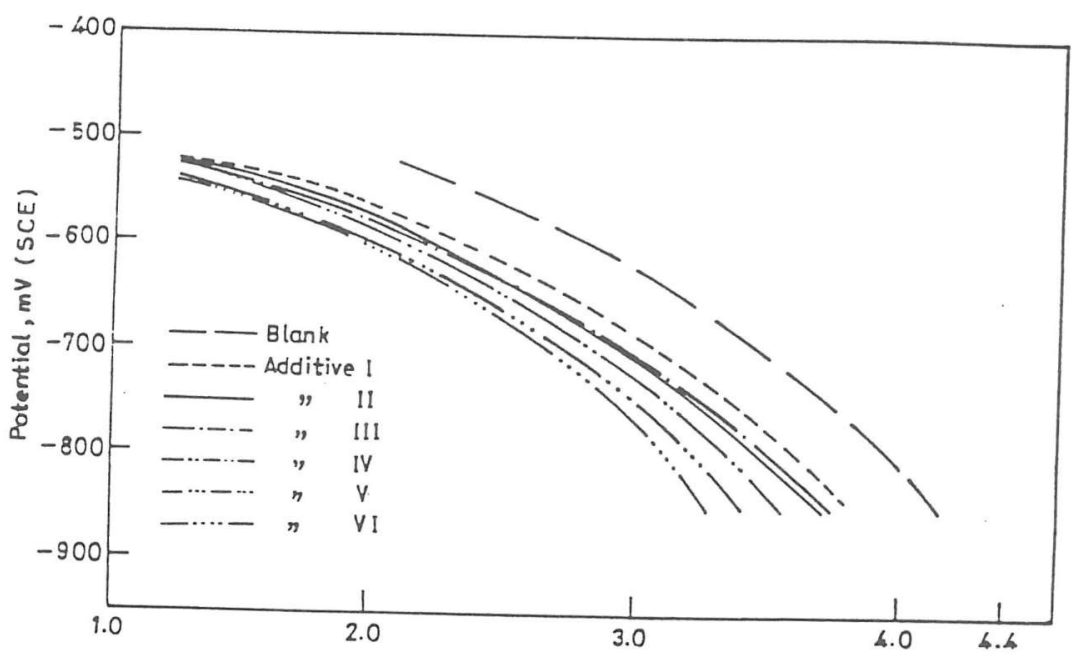

$\log i\left(\mu \mathrm{A} / \mathrm{cm}^{2}\right)$

Fig. 5: Cathodic polarisation curves of mild steel in the presence of different additives at $25^{\circ} \mathrm{C}$ either the isotherm of Langmuir or those of Temkin or Frumkin. The experimental equation of Frumkin's isotherm $(15,16)$ is

$$
\theta / 1-\theta \exp (\mathrm{f} \theta)=\mathrm{KC}
$$

where. ' $\mathrm{K}$ ' is the equilibrium constant for the adsorption reaction. ' $\mathrm{C}$ ' is the concentration of the inhibitor in mole litre ${ }^{-1}, \theta^{\prime} \theta^{\prime}$ is the degree of coverage and ' $f$ ' is parameter connected with the variation of adsorption energy with coverage. For $\mathrm{f}=0$, the Lamgmuir's isotherm is obtained and its validity is confirmed from the linearity of the $\log \theta /(1-\theta)$ vs $\log C$ plot. Temkin's isotherm results from the value of $f>0$ and hence, there should exist a linear dependence of $\theta$ upon $\log C$ (17).

Langmuir and Temkin's plots are shown in Fig. 6 and 7. For calculation of $\theta$ values, the inhibition efficiency obtained from electrochemical technique has been used. However, some deviation from linearity is expected in certain cases beyond $200 \mathrm{ppm}$ if $\theta$ is calculated from the weight loss data. In both cases. all investigated compounds give a straight line. at $25^{\circ} \mathrm{C}$. Thus, the adsorption of these inhibitors obey Langmuir as well as Temkin's adsorption isotherm.

The heat of adsorption was calculated, from the plots of $\log \theta /(1-\theta)$ vs. 1/T. for all the inhibitors at $100 \mathrm{ppm}$ as shown in Fig. 8. The values of heat of adsorption thus obtained are $-1.84,-3.68,-4.60,-5.52,-4.14$ and -4.14 $\mathrm{Kcal} / \mathrm{mole}$ for inhibitions I to VI. respectively. It appears from these values that inhibitor IV is most strongly adsorbed followed by inhibitor - III. inhibitors - V and VI. inhibitor - II and lastly inhibitor - I. The above sequence is not exactly similar to that obtained for their inhibition efficiency Probabily the size of the inhibitors also plays an important role along with the heat of adsorption in determining their inhibition efficiency. The inhibition efficiency increases regularly with the increase in the size from inhibitor - I to $\mathrm{Vl}$ 


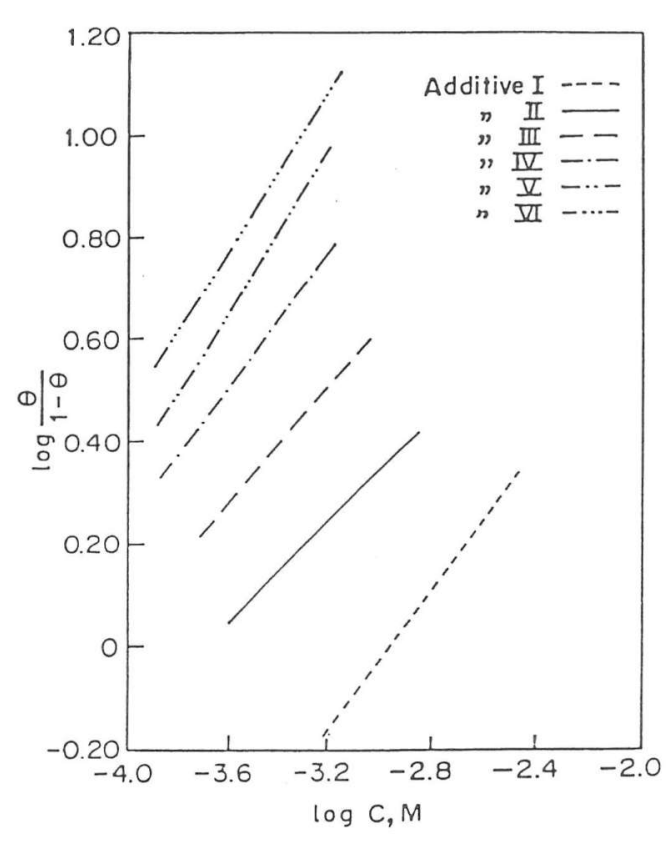

Fig. 6 : Langmuir plots for the additives at $25^{\circ} \mathrm{C}$

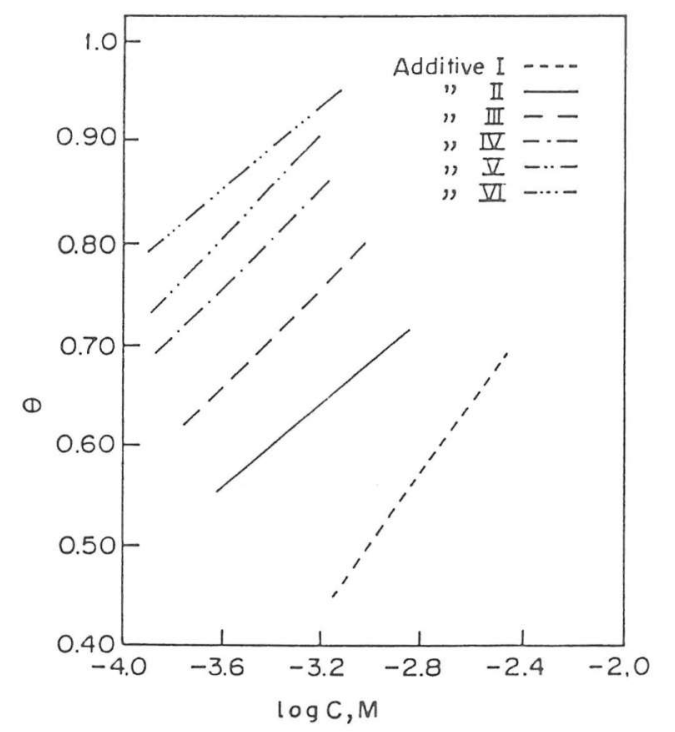

Fig. 7: Relation between surface coverage $\theta$ and $\log C$ for mild steel in $20 \% \mathrm{HCOOH}$, at $25^{\circ} \mathrm{C}$.

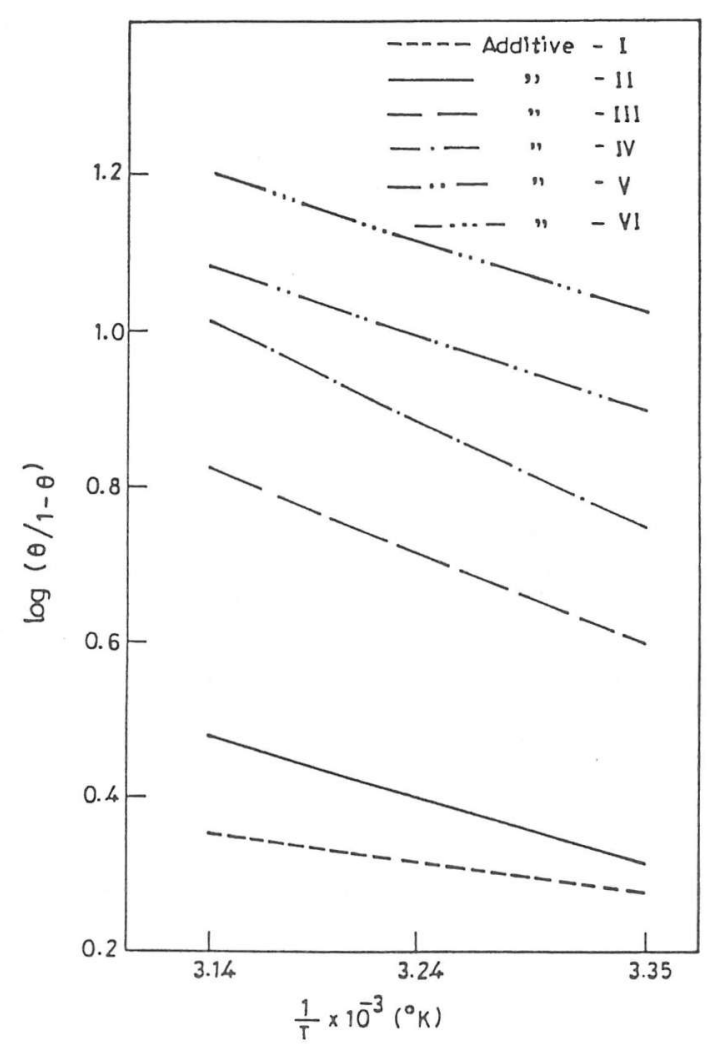

Fig. 8: Calculation of heat of adsorption.

Fig. 9 and 10 show the optical microphotographs for mild steel in $20 \%$ formic acid solution in the absence and presence of $200 \mathrm{ppm}$ of additive $\mathrm{V}$. at $1000 \mathrm{x}$ magnification. On comparing these microphotographs, it appears that in the presence of N-2[4-p-chlorophenyl] 5-o-methoxy phenyl azothiazolyl] thiocarbamide some change in the surface morphology due to the presence of the adsorbed layer of inhibitor molecules are observed. 


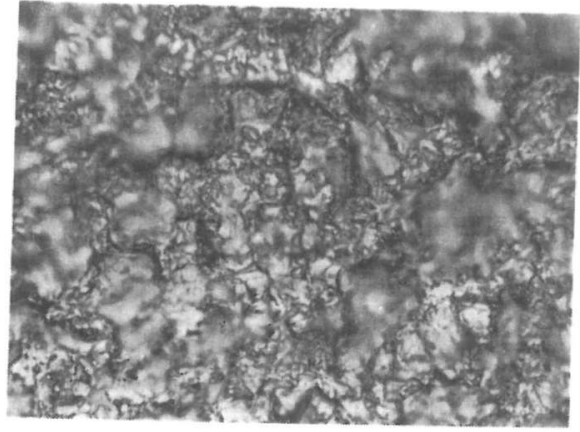

Fig. 9 : Mild steel in $20 \%$ formic acid solution (1000x

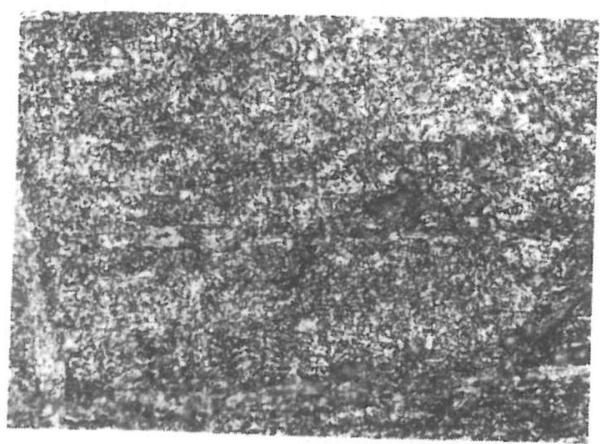

Fig. 10 : Mild steel in the presence of Additive VI $(1000 \mathrm{x})$

\section{CONCLUSIONS}

1. All the inhibitors tested are found to be effective for the corrosion of mild steel in $20 \%$ formic acid.

2. The inhibition efficiency of each tested inhibitor were found to be dependent on the inhibitor concentration and experimental temperature.
3. The order of the inhibition efficiency of the inhibitors may be represented as :

N-2 [4-p-chlorophenyl] 5-o-methoxy phenyl azothiazolyl] thiocarbamide > N-2 [4-p-chlorophenyl] 5-o-methyl phenyl azothiazolyl] thiocarbamide $>\mathrm{N}-2$ [4-p-chlorophenyl] 5-phenyl azothiazolyl] thiocarbamide $>\mathrm{N}-2$ [4-p-chlorophenyl] 2-thiazolyl] thiocarbamide $>2$-amino [4-p-chlorophenyl] thiazole $>$ thiourea

4. The adsorption of these molecules on the corroding surface could explain the observed inhibition efficiencies.

5. All the inhibitors were found to obey Langmuir, Temkin and Frumkin's adsorption isotherm in the whole range of concentration.

\section{REFERENCES}

1. M.M. Singh and A. Gupta. Bull. Electrochem., 12(1996) 511.

2. C. Chakraborty, M.M. Singh and C.V. Agarwal, Brit. Corros. J.. 18 (1983) 107.

3. D.D.N. Singh, M.M. Singh. R.S. Chaudhary and C.V. Agarwal. Electrochim. Acta, 26 (1981) 1051.

4. B. Mernari, H.EL Attari. M. Traisnel, F. Bentiss and M. Lagrenee. Corros. Sci, 40 (1998) 391.

5. D.D.N. Singh. R.S. Chaudhary, B. Prakash and C.V. Agarwal. Brit. Corros. J., 34 (1979) 235.

6. St. Ivascanu and V. Sfilip. Bul. Inst. Politech. Iasi, 13 (1967) 247.

7. I.N. Putilova, Zhur. Fiz. Khim.. 33 (1959) 226

8. K. Wippermann. J.W. Schultz. R. Kessel and J. Penniger, Corros. Sci., 32 (1991) 205. 
9. M.M. Singh and A. Kumar, Portugaliae Electrochim. Acta, 13 (1995) 173.

10. D.D.N. Singh, M.M. Singh, R.S. Chaudhary and C.V. Agarwal, J. Appl. Electrochem. 10 (1980) 587.

11. B.N. Upadhyay, Ph.D. Thesis, Banaras Hindu University (1994).

12. J.D. Talati and C.A. Patel, Trans SAEST (India), 13 (1978) 139.

13. M.M. Singh and A. Gupta. Mater. Chem. Phys. 46 (1996) 15.

14. T.P. Hoar and R.D. Holliday, J. Appl. Chem. 3 (1953) 502.

15. B.B. Damaskin, O.A. Pietrij and W.W. Batrakov, Adsorpcja Organiczeskich sojedinienij na electrodach. Moskwa (1968).

1.6. E. Gileadi, Electrosorption. Plenum Press. New York (1967).

17. S.H. Sanad, A.A. Ismail and A.A. El. Meligi, Bull. Electrochem. 11 (1995) 462 . 